\title{
HABITAT POHON PUTAT (Barringtonia acutangula) PADA KAWASAN BERHUTAN SUNGAI JEMELAK KABUPATEN SINTANG
}

\author{
Muhammad Syukur \\ Fakultas Pertanian Universitas Kapuas Sintang \\ Email : msyukur1973@yahoo.co.id
}

\begin{abstract}
ABSTRAKS: Penelitian ini bertujuan untuk mengetahui faktor biotik berupa vegetasi sekitar dan faktor abiotik meliputi tanah, suhu, kelembaban serta curah hujan pada habitat pohon Putat yang terdapat di kawasan berhutan sungai Jemelak desa Jerora Kecamatan Sintang Kabupaten Sintang. Hasil penelitian ini diharapkan dapat menambah ilmu dan pengetahuan terutama mengenai habitat pohon Putat yang terdapat pada kawasan Sungai Jemelak di Desa Jerora Kecamatan Sintang Kabupaten Sintang serta dapat dijadikan sebagai salah satu acuan dalam upaya pengelolaan dan penjagaan kelestarian pohonnya. Penelitian dilaksanakan dengan menggunakan metode petak tunggal. Penentuan petak pengamatan dilakukan secara purposive sampling (disengaja) pada areal yang banyak terdapat pohon Putat. Petak yang digunakan untuk pengamatan adalah petak tunggal yang berukuran $100 \mathrm{~m}$ x $60 \mathrm{~m}$. Didalam petak tunggal tersebut terdapat masing-masing $15 \mathrm{plot}$ pengamatan untuk tingkat pohon, tiang, pancang dan semai/tumbuhan bawah. Hasil penelitian ditemukan 4 (empat) jenis tumbuhan yang terdapat di sekitar pohon Putat, yaitu Belantik, Ijab, Jambu-Jambuan dan Ubah. Tanah pada lokasi penelitian memiliki pH 3,85 (Sangat Masam), Karbon Organik sebesar 1,52 \% (Rendah), N Total 0,13 \% (Rendah), $\mathrm{C} / \mathrm{N}$ rasio 11,69 \% (Sedang), K 0,11 (Rendah), Ca 1,95 (Sangat Rendah), Mg 0,67 (Rendah), Kejenuhan Basa (KB) 16,62 \% (Sangat Rendah), dan KTK 12,96 (Rendah) serta iklim yang sesuai dengan rerata curah hujan bulanan adalah 266,53 , rerata suhu udara bulanan $27,04{ }^{\circ} \mathrm{C}$, dan rerata Kelembaban Relatif bulanan adalah 84,17 (\%). Kawasan berhutan sungai Jemelak desa Jerora sebagai tempat penelitian dekat dengan pemukiman masyarakat dan terletak dikiri-kanan sungai seta cukup banyak ditemukan adanya aktivitas pemanfaatan serta terdapat kegiatan penambangan emas, untuk menjaga dan menjamin kelestarian fungsi kawasan terutama pohon Putat maka diperlukan upaya kerjasama yang sungguh-sungguh oleh pemerintah dan masyarakat.
\end{abstract}

Kata Kunci : Habitat Putat, Kawasan Berhutan Sungai Jemelak

\section{PENDAHULUAN}

Kabupaten Sintang Kalimantan

Barat yang dilalui oleh daerah aliran sungai (DAS) Kapuas memiliki tipe hutan yang kadang terendam oleh air tawar, terutama pada anak sungai Kapuas. Salah satunya adalah Sungai Jemelak dengan ciri kadang-kadang terendam oleh air tawar. Salah satu jenis yang paling banyak ditemukan pada kawasan berhutan di daerah rawa ini adalah pohon Putat (Barringtonia acutangula). Pohon Putat yang terdapat di sepanjang sungai Jemelak sangatlah dominan bila dibandingkan dengan jenis lainnya, bahkan pada bagian tertentu 
sangat sulit menemukan adanya pohon yang lain.

Pohon Putat bukan merupakan jenis yang komersil, sehingga tidak dikenal atau tidak termasuk kelompok jenis kayu perdagangan. Oleh karena hal tersebut, informasi mengenai jenis pohon ini sangat terbatas. Walaupun demikian sebagaimana jenis-jenis lainnya keberadaan pohon Putat sangatlah penting dari sisi fungsi ekologis terutama sebagai tempat bagi ikan berkembangbiak pada saat air pasang dan sebagai penahan lajunya erosi maupun longsor pada sempadan sungai.

Penggunaan kayu Putat oleh masyarakat selama ini hanya sebatas untuk kayu bakar, itupun sangat jarang karena api yang dihasilkan dari kayu ini tidak tahan lama dan arangnya sangat sedikit. Kelebihan pohon Putat terlihat dari kemampuannya yang dapat dengan mudah tumbuh dan berkembang bahkan dalam kondisi yang senantiasa terendam oleh air tumbuhan ini dapat hidup dengan baik. Kondisi ini memberikan gambaran bahwa, pohon Putat sesungguh mempunyai potensi yang sangat tinggi jika dijadikan sebagai jenis untuk rehabilitasi sempadan sungai. Mengetahui karakteristik dan ciri habitat suatu jenis tumbuhan menjadi sangat penting untuk sebuah upaya menjaga kelestarian jenis yang bersangkutan, begitu juga dengan jenis pohon Putat. Pohon Putat secara teoritis umumnya ditemukan tumbuh pada daerah rawa yang tergenang oleh air atau kadangkadang tergenang oleh air. Walaupun demikian, masih tetap diperlukan deskripsi spesifik tempat tumbuh pada suatu daerah tertentu, tidak terkecuali habitat pohon Putat yang terdapat pada kawasan berhutan Sungai Jemelak di Desa Jerora Kecamatan Sintang Kabupaten Sintang. Kawasan berhutan yang terdapat pada Sungai Jemelak di Desa Jerora Kecamatan Sintang Kabupaten Sintang merupakan areal yang mempunyai karakteristik spesifik. Warna air yang senantiasa gelap (air rawa), jenis tanah yang belum dapat dipastikan dan keanekaragaman jenis vegetasi yang belum terdata dengan baik, sehingga belum dapat ditentukan sifat dan karakteristik baik faktor biotik maupun abiotiknya. Pada sekitar kawasan ini juga terlihat adanya aktivitas penambangan emas rakyat, yang dikhawatirkan akan dapat merusak dan menggangu kelestarian jenis pohon Putat.

\section{METODOLOGI PENELITIAN}




\section{A. Metode Penelitian}

Metode penelitian yang digunakan untuk mengamati habitat pohon Putat yang terdapat pada kawasan berhutan di Sungai Jemelak Desa Jerora Kecamatan Sintang Kabupaten Sintang adalah metode petak tunggal. Penentuan petak pengamatan dilakukan secara purposive sampling (disengaja) pada areal yang banyak terdapat pohon Putat. Petak yang digunakan untuk pengamatan adalah petak tunggal yang berukuran $100 \mathrm{~m} \mathrm{x}$ $60 \mathrm{~m}$. Didalam petak tunggal tersebut terdapat masing-masing 15 plot pengamatan untuk tingkat pohon, tiang, pancang dan semai/tumbuhan bawah.

\section{B. Bahan Dan Alat Penelitian}

1. Bahan Penelitian

Bahan-bahan yang digunakan dalam penelitian ini adalah semua jenis vegetasi berkayu meliputi tingkat semai, pancang, tiang dan pohon yang ditemukan dalam petak pengamatan serta sampel tanah pada lokasi penelitian.

2. Alat Penelitian

Alat-alat yang digunakan dalam penelitian ini adalah Peta Lokasi, Kompas, Meteran dan tali, Parang, Cangkul atau penggali dan pipa paralon alat herbarium (alkohol $70 \%$, isolasi, gunting dan kertas Koran), Komputer, Kamera, Alat tulis menulis dan Altimeter.

\section{Pengumpulan Data}

Data - data yang dikumpulkan dalam penelitian ini meliput data primer dan data sekunder. Data primer didapat dengan cara melakukan pengamatan langsung di lokasi penelitian meliputi data jenis vegetasi berkayu, diameter dan jumlah individu mulai tingkat semai, pancang, tiang, dan pohon, sifat fisika dan sifat kimia tanah serta ketinggian tempat lokasi penelitian dari permukaan laut. Data sekunder diperoleh dari berbagai sumber yang meliputi iklim dan monografi lokasi penelitian.

\section{Pelaksanaan Penelitian}

1. Persiapan Penelitian

Kegiatan persiapan meliputi pengumpulan alat dan bahan yang akan digunakan untuk penelitian, serta observasi lapangan untuk menentukan letak petak pengamatan.

\section{Penentuan Petak Pengamatan}

Petak yang digunakan untuk pengamatan adalah petak tunggal yang berukuran 100 m x 60 m. Pada petak 
dibuat plot-plot pengamatan berukuran $20 \mathrm{~m}$ x $20 \mathrm{~m}$ untuk tingkat pohon (trees) sebanyak 15 buah, ukuran $10 \mathrm{~m}$ x $10 \mathrm{~m}$ untuk tingkat tiang (poles) sebanyak 15 buah, $5 \mathrm{~m} \times 5 \mathrm{~m}$ untuk tingkat pancang (saplings ) sebanyak 15 buah, dan $2 \mathrm{~m} \mathrm{x}$ $2 \mathrm{~m}$ untuk tingkat semai (seedlings) sebanyak 15 buah. Bentuk petak pengamatan selengkapnya dapat dilihat pada gambar berikut ini.

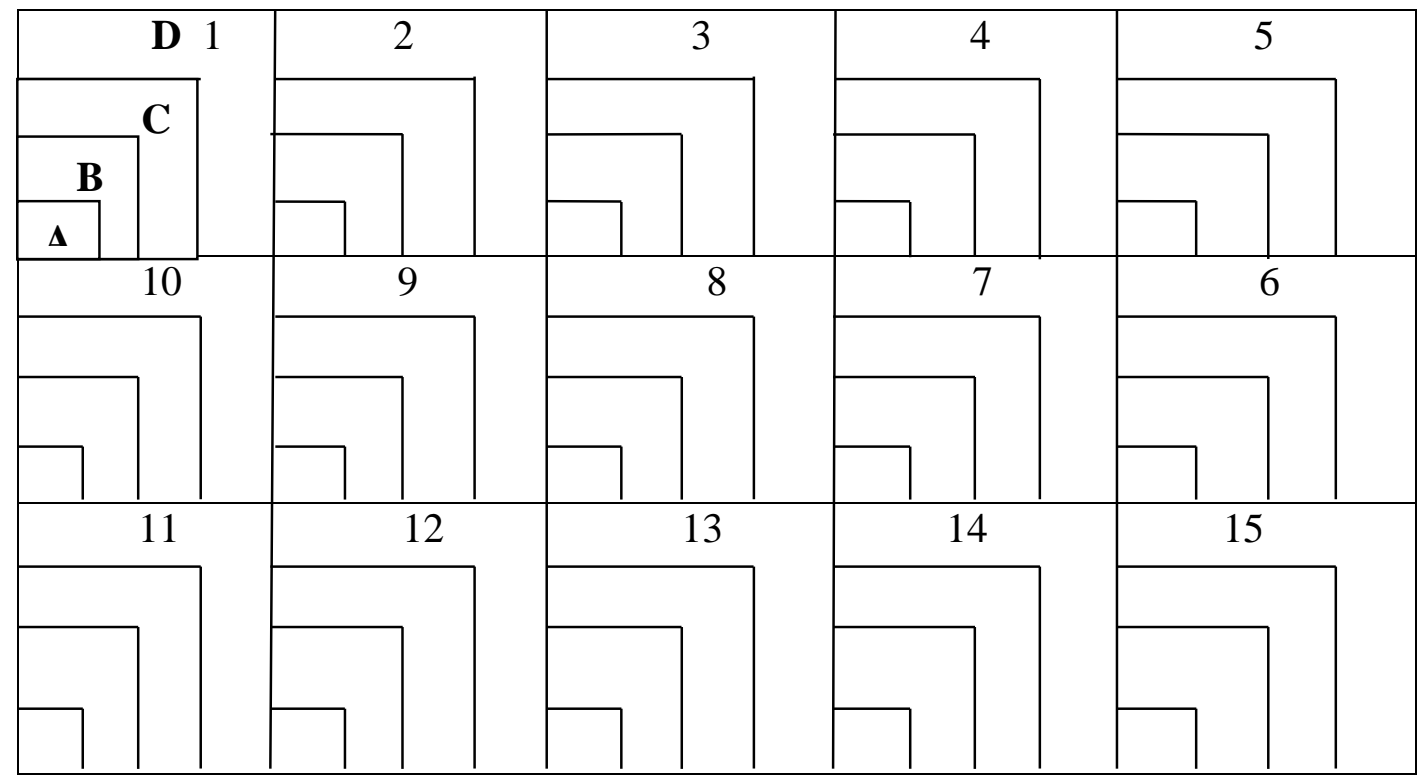

Gambar 1. Bentuk Petak Pengamatan.

\section{Keterangan :}
A : Petak $2 \times 2$ m, untuk tingkat semai (Seedlings) sebanyak 15 buah plot
B : Petak 5 x 5 m, untuk tingkat pancang (Saplings) sebanyak 15 plot
$\mathrm{C}$ : Petak 10 x $10 \mathrm{~m}$, untuk tingkat tiang (Poles) sebanyak 15 plot
D : Petak $20 \times 20 \mathrm{~m}$, untuk tingkat pohon (Trees) sebanyak 15 plot

3. Analisa Vegetasi

Setelah pembuatan petak pengamatan selesai, maka dilakukan analisa vegetasi yaitu mengidentifikasi dan inventarisasi seluruh jenis tumbuhan tingkat semai sampai pohon yang terdapat di sekitar pohon Putat. Jenis pengamatan dicatat nama jenis, diameter dan jumlah individu. Untuk pengenalan jenis, maka selama pelaksanaan penelitian analisa vegetasi dibantu oleh seorang penduduk setempat yang dianggap paling mengetahui tentang tumbuh-tumbuhan. 
Pengambilan sampel tanah dilakukan untuk pengamatan sifat fisika dan kimia tanah. Pengambilan sampel tanah di dalam petak pengamatan dilakukan secara purposive sampling pada 3 tempat dengan kedalaman $75 \mathrm{~cm}$ dari permukaan tanah, yaitu petak pengamatan nomor 1, 8 dan 15. Sampel tanah diambil dengan menggunakan pipa paralon dengan cara ditancapkan kedalam tanah. Tanah yang sudah diambil kemudian disimpan kedalam kantong plastik dan diberi label. Selanjutnya sampel tanah tersebut digabung menjadi satu, sehingga menjadi sampel komposite untuk kemudian dianalisis sifat fisik dan kimianya di Laboratorium.

5. Pengumpulan data sekunder

Data sekunder berupa curah hujan, kelembaban dan suhu rata-rata tahunan didapatkan dari Badan Meteorologi, Klimatologi dan Geofisika Susilo Sintang. Untuk data monografi lokasi penelitian didapat dari instansi terkait.

\section{E. Analisis Data}

Data yang dianalisis secara statistik hanya data hasil analisa vegetasi, sedangkan data hasil analisis sampel tanah data sekunder tidak dianalisis secara statistik. Analisis data hasil pengukuran dan pengamatan pada petak pengamatan berupa Indeks Nilai Penting (INP) menurut Soerianegara dan Indrawan (2005).

\section{F. Tempat dan Waktu Penelitian}

Penelitian dilakukan pada kawasan berhutan Sungai Jemelak Desa Jerora Kecamatan Sintang Kabupaten Sintang. Waktu penelitian kurang lebih 1 (satu) bulan efektif di lapangan.

\section{HASIL DAN PEMBAHASAN}

\section{A. Vegetasi Sekitar Pohon Putat}

Berdasarkan hasil penelitian dan analisis data, maka diketahui bahwa jenis-jenis vegetasi yang dominan terdapat di sekitar pohon Putat untuk tingkat semai adalah Ijab (INP :77,2516), Ubah (INP : 59,3944), Jambu-Jambuan (INP : 47,5155) dan Belantik (INP : 15,8385). Hasil penelitian dan analisis data vegetasi tingkat pancang, maka diketahui bahwa jenis-jenis vegetasi yang dominan terdapat di sekitar pohon Putat secara berurutan adalah Ubah (INP:134,1751), Jambu-Jambuan (INP:111,9529) dan Belantik (INP:53,8721). Berdasarkan hasil penelitian dan analisis data vegetasi tingkat tiang, maka diketahui bahwa 
jenis-jenis vegetasi yang dominan di sekitar pohon Putat secara berurutan adalah Ubah (INP:129,7860), JambuJambuan (INP : 115,1918) dan Belantik (INP : 55,0222).

Berdasarkan hasil penelitian dan analisis data vegetasi tingkat pohon, maka diketahui bahwa jenis-jenis vegetasi yang dominan di sekitar pohon Putat secara berurutan adalah Ubah (INP : 142,4528), Jambu-Jambuan (INP : 105,2585) dan Belantik (INP : 52,2887).

\section{B. Analisis Tanah}

Sifat-sifat tanah berdasarkan hasil analisis pada Laboratorium lyman Research Centre Soil Analysis Result dibandingkan dengan kriteria tanah menurut Pusat Penelitian Tanah Bogor (PPT) Tahun 1983, maka diketahui bahwa memiliki pH 3,85 (Sangat Masam), Karbon Organik sebesar 1,52 $\%$ (Rendah), N Total 0,13\% (Rendah), $\mathrm{C} / \mathrm{N}$ rasio $11,69 \%$ ( Sedang), K 0,11 (Rendah), Ca 1,95 (Sangat Rendah), Mg 0,67 (Rendah), KTK 16,43 (Rendah) dan

79PIPER

No.

23

c. remoanasan

Berdasarkan hasil penelitian sebagaimana uraian sebelumnya diketahui bahwa vegetasi yang dominan terdapat di sekitar pohon Putat untuk tingkat semai adalah Ijab, Ubah, JambuJambuan dan Belantik. Jenis-jenis vegetasi yang dominan untuk tingkast pancang secara berurutan adalah Ubah, Jambu-Jambuan dan Belantik. Untuk tingkat tiang dan pohon vegetasi yang dominan di sekitar pohon Putat secara berurutan adalah Ubah, Jambu-Jambuan dan Belantik. Hasil analisis vegetasi menunjukan bahwa sesungguhnya memang jenis-jenis tersebut adalah yang paling sering terdapat di sekitar pohon Putat yang menghendaki kondisi lingkungan yang terbuka. Artinya untuk tumbuh dan berkembangnya pohon Putat diperlukan areal yang terbuka dengan pencahayaan cukup tetapi walaupun demikian dijumpai juga beberapa diantaranya dapat tumbuh dengan baik dibawah naungan, sehingga jenis pohon Putat dapat hidup dengan baik pada kondisi yang kurang pencahayaan maupun pada kondisi pencahayaan yang cukup/tinggi (terbuka).

Terhadap tanah berdasarkan hasil

$\begin{array}{lll}\text { Volume } & 12 & \text { Oktober }\end{array}$ soll Allalysis uाkelanul vallwa IUKası penelitian mempunyai pH 3,85, Karbon Organik sebesar 1,52\%, N Total 0,13\%, $\mathrm{C} / \mathrm{N}$ rasio $11,69 \%, \mathrm{~K} 0,11, \mathrm{Ca} 1,95, \mathrm{Mg}$ 
0,67, KTK 16,43 dan KB 16,62. Selain

itu diketahui juga sifat fisik tanah dengan kandungan liat 49,91\%, Debu 49,72\%, Pasir Halus 0,21 \% dan Pasir Kasar 0,17 $\%$, dengan kondisi ini dapat dinyatakan sebagai tanah Liat Berdebu. Hasil analisis terhadap habitat yang meliputi vegetasi sekitar dan sifat fisik-kimia tanah menunjukkan bahwa, untuk tumbuh dan berkembangnya pohon Putat menghendaki keadaan yang spesifik. Pohon Putat pada lokasi penenlitian tumbuh dengan sangat dominan dibandingkan dengan jenis lainnya. Hal ini berbeda dengan pohon Putat yang biasa ditemukan hidup berdampingan dengan beberapa jenis lain (tidak dominan), seperti yang biasa ditemukan di sepanjang sungai Kapuas. Hasil penelitian ini memberikan asumsi baru bahwa, Putat dapat tumbuh dengan baik pada kondisi habitat seperti di sungai Jemelak atau mungkin saja inilah kondisi ideal bagi pertumbuhannya, sehingga sangat dominan terhadap penguasaan tempat tumbuh. Areal hutan yang terbuka, tanah dengan tekstur liat berdebu, warna tanah abu-abu yang merupakan tanah hasil sedimentasi telah nyata dapat memacu pertumbuhan dan perkembangan pohon Putat secara maksimal, sehingga ditemukan pohon
Putat yang sangat dominan dibandingkan di tempat yang lain.

Terdapat kesesuaian habitat penelitian dengan syarat bagi tumbuh dan berkembangnya pohon Putat. Kesesuaian ini terlihat dengan jelas antara hasil analisis dan keadaan lokasi penelitian yang terendam oleh air cukup dalam pada waktu air pasang dengan kajian teoritis yang menyatakan bahwa secara umum pohon Putat dapat tumbuh dengan baik pada berbagai tipe tanah, seperti tanah alluvial, tanah berpasir dan tanah liat dan tumbuh dengan baik pada kondisi tanah yang kadang-kadang terendam oleh air. Pohon Putat adalah jenis yang dianggap paling baik kemampuan beradaptasi terhadap kondisi air. Pohon ini bahkan tidak mati walaupun sepanjang tahun terendam oleh air. Pohon ini sangat cocok dijadikan pohon penahan lajunya erosi dan longsor pada pinggir sungai, karena memiliki sistem perakaran yang sangat baik dalam meningkat daya erodibilitas tanah (menahan lajunya erosi tanah). Umumnya pohon Putat menghendaki tempat tumbuh dengan Ketinggian < 500 meter dari permukaan laut, curah hujan berkisar antara 2000 - 4000 $\mathrm{mm} /$ tahun, temperatur antara $18-30{ }^{\circ} \mathrm{C}$ 
dengan tanah yang teksturnya ringan sampai sedang.

Pohon Putat secara umum bukan jenis kayu yang banyak dimanfaat oleh masyarakat Kabupaten Sintang Kalimantan Barat, tetapi seiring dengan semakin berkurangnya kayu yang dapat dimanfaatkan oleh masyarakat, jenis ini pun dapat menjadi alternatif. Kayu Putat oleh masyarakat setempat pada saat ini kayunya hanya digunakan untuk kayu bakar. Pada hal potensi yang terbesar bagi pohon Putat adalah sebagai pohon rehabilitasi sepanjang sungai untuk menahan lajunya erosi dan longsor. Sifat pohon Putat yang tahan terendam oleh air sepanjang tahun, dapat tumbuh dengan baik pada lahan terbuka dan tidak menghendaki syarat yang spesifik untuk tumbuh dan berkembangnya adalah potensi terbesar (sangat cocok) digunakan sebagai pohon rehabilitasi kiri-kanan sungai.

\section{PIPER}

No. 23

beruasarkan nası penentıan berupa analisis vegetasi dan tanah sebagai habitat pohon Putat pada lokasi penelitian, maka dapat disimpulkan sebagai berikut;
1. Terdapat 4 (Empat) jenis tumbuhan yang terdapat di sekitar pohon Putat, yaitu Belantik, Ijab, Jambu-Jambuan dan Ubah.

2. Tanah pada lokasi penelitian memiliki pH 3,85 (Sangat Masam), Karbon Organik sebesar 1,52 \% (Rendah), N Total 0,13\% (Rendah), $\mathrm{C} / \mathrm{N}$ rasio 11,69\% (Sedang), K 0,11 (Rendah), Ca 1,95 (Sangat Rendah), Mg 0,67 (Rendah), Kejenuhan Basa (KB) 16,62\% (Sangat Rendah), dan KTK 12,96 (Rendah) serta iklim yang sesuai dengan rerata curah hujan bulanan adalah 266,53, rerata suhu udara bulanan $27,04{ }^{\circ} \mathrm{C}$, dan rerata Kelembaban Relatif bulanan adalah $84,17(\%)$.

\section{B. Saran}

Kawasan berhutan sungai Jemelak desa Jerora sebagai tempat penelitian dekat dengan pemukiman masyarakat dan terletak dikiri-kanan sungai seta
Volume
12
Oktober kegialan penamoangan emas, untuk menjaga dan menjamin kelestarian fungsi kawasan terutama pohon Putat, maka diperlukan upaya kerjasama yang sungguh-sungguh antara pemerintah dan masyarakat. 


\section{DAFTAR PUSTAKA}

Hardjowigeno, S. 1987. Ilmu Tanah. Edisi Baru. Akademika Pressindo. Jakarta.

Kristianto dan Listya Mustika Dewi, 2012. Jenis Kayu Untuk Mebel. Pusat Penelitian dan Pengembangan Keteknikan Kehutanan dan Pengolahan Hasil Hutan, Badan Penelitian dan Pengebangan Kehutanan. Kementerian Kehutanan. Bogor.

MacKinnon, Gusti Hatta, Hakimah Halim dan Arthur Mangalik. 2000. Ekologi Kalimantan. Seri ekologi Indonesia Buku III. Prenhallindo. Jakarta.

Odum.E.P. 1993. Fundamental of Ecology, Edisi Kedua, W . B. Solunder Company, Philadelphia

Samingan, T. 1986. Tipe-tipe Vegetasi. Universitas Gadjah Mada. Yogyakarta.

Simon, H. 1990. Pengantar Ilmu Kehutanan. Fakultas Kehutanan. Universitas Gadjah Mada, Yogyakarta.

Soerianegara, I. dan Indrawan, A. 2005. Ekologi Hutan Indonesia. Fakultas Kehutanan IPB. Bogor.

Winarto, B. 2006. Kamus Rimbawan. Yayasan Bumi Indonesia Hijau. Jakarta. 